Ideally, we should have liked to have included four treatment groups in our study: abrupt and gradual withdrawal, each with and without propranolol. Such a study was, however, impractical for us at the time. We therefore restricted it to the two groups described in our paper, as these seemed to be the most widely used and effective treatment regimes at the time the study was launched. We agree that our study does not dismiss the possibility of propranolol being of some use in benzodiazepine withdrawal in some patients. However, it is of note that in our sample, patients slowly withdrawn were successful in their efforts at withdrawal without suffering significant withdrawal symptoms. In the slow withdrawal group, therefore, few patients would have needed any adjunct to the slow withdrawal regime. It is also notable that in the abrupt withdrawal group, the addition of propranolol did not prevent patients from suffering considerable withdrawal symptoms that in many cases led to failure to complete the withdrawal process.

We intended to determine whether the advantages of slow withdrawal could be offset by using propranolol, thus allowing abrupt withdrawal to be successful in a similar proportion of cases. We believe that we have shown that this is not the case.

TIM CANTOPHER

Nancy Cleave

GuY EDWARDS

S. OLIVIERI

Abraham Cowley Unit
St Peters Hospital
Guildford Road
Chertsey, Surrey

\section{Limitations of double-blind trials}

SIR: Double (Journal, August 1990, 157, 300) appears to have misunderstood the argument I put forward (Journal, February 1990, 156, 282). The valuable article by Kramer \& Shapiro (1984) he cites does not denigrate the value of the randomised controlled trial, but indeed upholds it as the method of choice for evaluation of therapeutic interventions, although pointing out several issues that are important to the design, execution and interpretation of a clinical trial. One of these issues is the possibility of bias arising when the desirable property of double-blindness is not attained, a possibility I certainly accept as impairing the interpretation of the results of a study.

Kramer \& Shapiro suggested a strategy of asking participants to guess, on completion of the trial, which treatment they received, but solely as a means of assessing possible bias due to unblinding. They explicitly upheld the principle of analysis by 'intention to treat' and did not advocate stratification of the statistical analysis by blinding status. In a trial of ascorbic acid for the common cold, cited both by Dr Double and by Kramer \& Shapiro, Karlowski et al (1975), having found that many more participants guessed their treatment correctly than guessed incorrectly, went on to examine evidence for efficacy in two subgroups separately, those who 'knew' which treatment they had received and those who 'did not know'. These subgroup labels were in fact misleading: the 'knew' group consisted of 79 subjects who guessed correctly; the 'did not know' group comprised not only 88 who did not offer a guess but also 23 who guessed incorrectly. This suggests that some 23 of the 79 who guessed correctly were doing no more than guessing; the 'did not know' group would more appropriately be supplemented by transferring to it 23 of the 'knew' group, either chosen randomly or by a weighted analysis.

Failure to demonstrate an advantage for active treatment in the 'did not know' group, as occurred in Karlowski et al's study, need not imply that the benefit observed in an intention-to-treat analysis was illusory, for such a failure can arise in three ways. Firstly, the 'did not know' group may not be defined symmetrically (i.e. to contain as many correct guesses as incorrect ones). Karlowski et al failed in this respect, and the recommendations of Oxtoby et al (1989) seem to suggest doing just what Karlowski et al did. Secondly, problems can result from predominantly correct guessing, arising because of therapeutic efficacy. Karlowski et al were not able to exclude this and Oxtoby et al would be careful to distinguish it from guessing on the basis of sideeffects. Thirdly, failure can arise from the depletion of the number of subjects included, and consequently of the statistical power to demonstrate a difference in effectiveness between treatments. This can seriously impair ones ability to demonstrate a null difference, as well as one's ability to demonstrate a substantial one.

The implication is clearly that the issue of maintenance of blindness should be dealt with as far as possible by good study design and execution. This will not always avoid the problem, but when it does, it will be much more satisfactory than a somewhat artificial salvaging operation in the statistical analysis. Often the results of a trial will fail to be as definitive as one would like, but will generally be subject to fewer limitations than inferences from purely observational studies. Interpretation of results is inevitably of the greatest importance; equally inevitably, the 
scope for controversy of interpretation will always be particularly wide in psychiatry.

R. G. NEWCOMBE
Department of Medical Computing and Statistics
University of Wales College of Medicine
Heath Park
Cardiff CF4 4XN

\section{References}

Karlowski, T. R., Chalmers, T. C., Frenkel, L. D. et al (1975) Ascorbic acid for the common cold. Journal of the American Medical Association, 231, 1038-1042.

KraMier, M. S. \& Shaptro, S. H. (1984) Scientific challenges in the application of randomised trials. Journal of the American Medical Association, 252, 2739-2745.

OxTOBY, A., JONEs, A. \& ROBnNSON, M. (1989) Is your 'double-blind' design truly double-blind? British Journal of Psychiatry, 155, 700-701.

\section{The Lomax afiair}

SIR: Budden (Journal, August 1990, 157, 301-302) is concerned that my account of the Lomax affair (Journal, February 1990, 156, 180-187) gives the impression that asylums were "places of brutality and inhumanity in general". He believes that the unusual conditions prevailing at the end of the first world war were responsible among other things for the high death rate among patients. Lomax was well aware that the shortages because of the war created great difficulties for asylum management. However, his indictment of asylum administration went much further than accounts of brutality, malnutrition and a high mortality rate. He believed that the English asylum system had become a closed-off world, with ineffective outside control, which existed "merely to confine the insane". Senior and presumably well informed civil servants in the Ministry of Health did not believe that the war was a sufficient explanation for the appalling conditions: Mr (later Sir Percy) Barter wrote, in a confidential minute to the Health Minister on Lomax's criticism, “... allowing for irregularities due to war conditions, the indictment is I believe in the main well founded".

My reason for unearthing the Lomax affair was not to open a debate about how good or bad conditions in English asylums were over 70 years ago. Rather, I was interested in how changes in mental health services are brought about and the role of an outsider who chose to challenge the psychiatric establishment. By 1924, all observers agreed that major reforms were necessary.

The editorialist in the Lancet commenting on my paper justifies reviving the Lomax affair thus: “. . . injustice is always wrong, and it is better to put it right seventy years later than to let it persist". She or he comments further that in the face of the current neglect and ill treatment of mentally ill people in the community, "Britain may need another Montagu Lomax in the 1990s, with a wider remit" (Editorial, 1990).

Institut Universitaire de Médecine Légale

T. W. HARDING 9, Avenue de Champel

1211 Genève 4

Switzerland

Reference

EdroRial (1990) The Lomax affair. Lancet, i, 264-265.

\section{Education for the 21 st century}

SIR: Cawley (Journal, August 1990, 157, 174-181) is correct in drawing our attention to the education of the psychiatrist of the 21 st century. His remarks on the role of the Collegiate Trainees Committee (CTC) are thought-provoking. Indeed, in the past 11 years of its existence the CTC has put forward many new ideas of which some have been accepted by the College rather quickly, and others abandoned quietly. The acceptance or the rejection has not depended on the goodness of the idea but the 'goodness of fit'. This goodness of fit is what we would call 'fitting in with the system'. However, this process of 'fitness' depends upon not only the activity of the trainees but also the receptivity of the College. Unfortunately, the CTC does not have enough power in its own right to put through changes. Also, the inexperience of trainees in the political arena means that even though they may put forward fresh thinking and ideas in an enthusiastic manner, their naivety and lack of political clout and often lack of support among senior colleagues may cost them dearly. From local experience, it is apparent that trainees often are scared to put their names on paper in favour of anything that may be perceived controversial and thence prejudicial to their careers.

Certainly over the last few years, the CTC has led the way on many issues. Public image of psychiatry was discussed even before the Public Education Officer was appointed by the College. The role of training in community care settings was put forward by the CTC. Of the seven points that Professor Cawley has raised, the CTC has specifically looked at the practice of psychiatry in primary care, the role of management and audit in training, part-time training for 